\title{
The prevalence of post-traumatic stress disorder symptoms in relatives of severe trauma patients admitted to the intensive care unit
}

\author{
L. V. Pillai, D. Ambike, S. Husainy, N. Vaidya, S. D. Kulkarni, S. Aigolikar
}

Aim: To study the prevalence of symptoms suggestive of post-traumatic stress disorder in relatives of
severe trauma patients admitted to the ICU. Materials and Methods: 177 relatives of trauma patients
admitted to the ICU were studied to evaluate the negative psychological impact resulting from this admission
by using the impact of event scale-revised [IES-R]. About 76 of these relatives could be followed up again
with questionnaire after 2 years. Result: Of the 177 relatives, $85(48 \%)$ were males and $92(52 \%)$ females
with no statistically significant difference in their scores. About 7 days after admission, $34-54 \%$ of the 177
relatives had moderate and $19-41 \%$ had severe symptoms suggestive of PTSD. For the 76 relatives who
participated in both 2002 and 2004 , symptoms suggestive of PTSD were moderate in $39-61 \%$ and severe
in $12-39 \%$ initially. After 2 years the scores were moderate in $12-14 \%$ and severe in $4-5 \%$. Maximum scores
amongst the three subscales were for hyperarrousal symptom with mean scores of $2.1 \pm 1$. In the group-
which could be followed up after 2 years, initially $79 \%$ of the respondents had sum of IES-R scores ?26
suggesting severe symptoms, which declined to $14 \%$ after 2 years. Conclusion: Findings of this study
suggest that $79 \%$ of the relatives of severe trauma patients develop PTSD symptoms following ICU admission.
In most, the scores reduced with time but $14 \%$ continued to have severe scores at the end of 2 years
suggesting the presence of persisting psychological disturbance in them.
Key words: Post-traumatic stress disorder, psychological symptoms, trauma

The unexpectedness of an accident and the subsequent intensive care admission can be a stressful event for the relatives of trauma victims. Anxiety in the relatives during the hospitalization is understandable but whether it leads to later psychological morbidity has been the focus of many recent studies. ${ }^{[1-4]}$ Various factors combine to create a psychologically devastating condition in relatives of ICU patients. Major issues are lack of

\footnotetext{
From:

Department of Critical Care Medicine, Lokmanya Hospitals, Chinchwad, Pune, India

Correspondence:

Dr. Lalitha V. Pillai, Department of Critical Care Medicine, Lokmanya Hospitals,

Chinchwad, Pune - 411033 , India.

E-mail: Ialithapillai@rediffmail.com
}

information about the nature of the illness, incessant reminders of the potential complication during consent for investigations, procedures or surgery, financial burden of hospitalization and most importantly restricted access to the patient.

Acute stress disorder is associated with increased risk of post-traumatic stress disorder (PTSD). ${ }^{[5]}$ Diagnosis of PTSD was introduced in the $3^{\text {rd }}$ edition of diagnostic manual of mental disorder (DSM). ${ }^{[6]}$ It is a severe condition characterized by persistent re-experiencing of the event, avoidance of event-related stimuli and symptoms of increased arousal. According to DSM-1V, the traumatic event criterion includes two component 
criteria. Criterion $1 \mathrm{~A}$ stipulates, 'The person experienced, witnessed or has been confronted with an event or events that involved actual or threatened death or serious injury or a threat to the physical integrity of self or others'. While criterion 2 stipulates 'the person's response involved intense fear, helplessness or horror'. As per this definition, we felt that the next of kin of trauma victims fulfilled both the criterion and therefore were at risk for developing symptoms suggestive of PTSD. Even though both physical and emotional threats are implied in the criterion, earlier research focused on physical threat criteria of severe trauma. In this paper it is proposed to study the emotional threat, i.e. the effect of trauma ICU admission on relatives (next of kin) and to decide if there was a negative psychological sequel following trauma ICU admission by using the Horowitz's Impact of Event -Revised Scale (IESR). ${ }^{[7]}$ Although IES-R is not meant to be a proxy for the diagnosis of PTSD, it has been used frequently both in trauma and nontrauma related studies alone or along with other scales of psychiatric illness. ${ }^{[1-4,8]}$

\section{Materials and Methods}

Relatives (spouse, parent or sibling who were identified as next of kin) of patients who were admitted in the ICU (July-Dec. 2002), as a result of severe trauma and consented to answer the questions participated in the study. They were all above 18 years of age and literate. The patients had similar severe injuries (polytrauma or head injuries with GCS $>8$ ) requiring ICU stay of $<7$ days.

\section{Statistical analysis}

All values are reported as mean and SD for normally distributed variables. Data are presented in actual numbers and percentages. If a difference was found, a paired $t$-test was used to compare groups at each time point. Correlations between variables were calculated by the Pearson correlation coefficient. A $P$ value $<0.05$ was considered significant. Data were analyzed using SPSS 12.0 software.

\section{Procedure}

IES-R is a standardized measure of PTSD symptoms. It is a 22-items scale, which taps into intrusion, avoidance and hyperarrousal symptoms. Respondents are instructed to rate on a 5 point Likert scale from 0 (not at all) to 4 (extremely) how affected they felt by the traumatic event during the preceding 7 days. As the event 'accident' was a specific event occurring suddenly at a specific time it was considered as an appropriate event for administration of IES-R scale. There was no modification in the wording order or content when translating into the language of the respondent and was administered by a clinical psychologist.

Subsequently both the mean score in each group, i.e., intrusion avoidance and hyperarrousal symptoms along with the standard deviation (SD) as well as the sum of the scores were considered while analyzing the data. Sum of the score $<26$ was considered as severe. ${ }^{[9]}$

\section{Result}

About 177 relatives agreed to answer the questionnaire. Of these 85 (48\%) were male and 92 (52\%) were female. There was no statistically significant difference between the males and females in their scores $(P=0.7558)$. Of the respondents $22 \%$ were graduates $20 \%$ were school dropouts and $58 \%$ had school level education, i.e. majority had at least school level education. Abour $60 \%$ belonged to middle income group earning between Rs. 5000-10000. None were below poverty line.

After 2 years later 80 (45\%) of the original respondents could be traced. About 76 (43\%) responded to the telephonic interview. About four were abusive and refused to answer saying all this was a gimmick. Rest (97) could not be traced due to change in address, telephone numbers or had no telephones. Eleven of the patients had died during this interval. One relative was extremely thankful to be able to speak because she had been feeling very depressed and had many guilt feelings.

The mean IES-R scores on Intrusion, Arousal and Hyperarrousal subscales for all 177 respondents are as shown in Table 1. The correlation between avoidance and intrusion subscale was 0.54 . Table 2 compares the mean IES-R scores of the same group of respondents in 2002 and 2004.

Analysis of the initial data of 177 respondents in 2002, suggests that symptoms of PTSD were moderate in 34$54 \%$ and severe in $19-41 \%$ of the respondent's ([Table 1] lowest and highest scores). In the 76 cases who responded both in 2002 and 2004, symptoms suggestive of PTSD were moderate in $39-61 \%$ and severe in $12-39 \%$ initially [Table 2] but showed significant reduction at the end of 2 years. The symptoms were now moderate in $12-14 \%$ and 


\begin{tabular}{llcc}
\hline \multicolumn{3}{l}{ Table 1: The initial mean IES-R score } & \\
\hline \multirow{4}{*}{ Avoidance } & \multicolumn{2}{l}{$\mathbf{2 0 0 2}$ (177 cases) } \\
\cline { 3 - 4 } & & No. & $\%$ \\
& Normal/mild (0-1.00) & 29 & 16.4 \\
& Moderate (1.01-2.49) & 96 & 54.2 \\
Intrusion & Severe (2.5-4) & 52 & 29.4 \\
& & 177 & 100 \\
& Normal/mild (0-1.00) & 48 & 27 \\
Hyperarousal & Moderate (1.01-2.49) & 96 & 54 \\
& Severe (2.5-4) & 33 & 19 \\
& & 177 & 100 \\
& Normal/mild (0-1.00) & 44 & 25 \\
& Soderate (1.01-2.49) & 61 & 34 \\
& Severe (2.5-4) & 72 & 41 \\
& & 177 & 100 \\
\hline
\end{tabular}

\begin{tabular}{|c|c|c|c|c|c|}
\hline \multirow[t]{2}{*}{ Item } & \multirow[t]{2}{*}{ Levels } & \multicolumn{2}{|c|}{$\begin{array}{c}2002 \\
\text { (76 cases) }\end{array}$} & \multicolumn{2}{|c|}{$\begin{array}{c}2004 \\
\text { (76 cases) }\end{array}$} \\
\hline & & No. & $\%$ & No. & $\%$ \\
\hline \multirow[t]{4}{*}{ Avoidance } & Normal/mild $(0-1)$ & 13 & 17 & 61 & 80 \\
\hline & Moderate (1.01-2.49) & 46 & 61 & 11 & 14 \\
\hline & Severe $(2.5-4)$ & 17 & 22 & 4 & 5 \\
\hline & Total & 76 & 100 & 76 & 100 \\
\hline \multirow[t]{4}{*}{ Intrusion } & Normal/mild (0-1) & 21 & 28 & 64 & 84 \\
\hline & Moderate (1.01-2.49) & 46 & 61 & 9 & 12 \\
\hline & Severe $(2.5-4)$ & 9 & 12 & 3 & 4 \\
\hline & Total & 76 & 100 & 76 & 100 \\
\hline \multirow[t]{4}{*}{ Hyperarousal } & Normal/mild $(0-1)$ & 16 & 21 & 62 & 82 \\
\hline & Moderate (1.01-2.49) & 30 & 39 & 10 & 13 \\
\hline & Severe $(2.5-4)$ & 30 & 39 & 4 & 5 \\
\hline & Total & 76 & 100 & 76 & 100 \\
\hline
\end{tabular}

severe in 4-5\% [Table 2]. Table 3 and Figure 1 show reduction in the mean subscales over time in this group.

As indicated in Table 4, if the sum of the subscales is considered, it is seen that only $3 \%$ had normal scores while $79 \%$ had scores suggestive of severe psychological distress seven days after the ICU admission of their relative. About $76 \%$ of the 76 relatives in 2002 who could be followed up for 2 years had sum of the scores $\leq 26$ suggesting severe stress, although normalization of symptoms in $47 \%$ of them occurred by the end of 2 years [Table 5]. These data also show that at the end of 2 years 38 and $14 \%$ continued to have moderate and severe scores, respectively.

\section{Discussion}

It is accepted that relatives of ICU patients will be under severe stress as long as their patients are critically ill but whether this stress predisposes them to chronic psychological illness is a cause for concern. It has been observed that the intensity of psychological response of an individual to a psychologically traumatic experience is associated with a degree of controllability, predictability,

\begin{tabular}{|c|c|c|c|c|c|c|}
\hline \multirow[t]{2}{*}{ Item } & \multicolumn{2}{|c|}{$\begin{array}{c}2002 \\
\text { (177 cases) }\end{array}$} & \multicolumn{2}{|c|}{$\begin{array}{c}2002 \\
\text { (76 cases) }\end{array}$} & \multicolumn{2}{|c|}{$\begin{array}{c}2004 \\
\text { (76 cases) }\end{array}$} \\
\hline & Mean & SD & Mean & SD & Mean & SD \\
\hline Avoidance & 1.91 & 0.86 & 1.8 & 0.8 & 0.7 & 0.7 \\
\hline Intrusion & 1.62 & 0.86 & 1.5 & 0.7 & 0.6 & 0.7 \\
\hline Hyperarousal & 2.03 & 1.12 & 2.1 & 1.0 & 0.7 & 0.8 \\
\hline Total & 5.56 & 2.44 & 5.4 & 2.1 & 1.9 & 2.1 \\
\hline
\end{tabular}

Table 4: Severity distribution according to sum of IES-R score

\begin{tabular}{|c|c|c|c|c|c|}
\hline \multirow{2}{*}{\multicolumn{3}{|c|}{ Sum }} & \multicolumn{3}{|c|}{2002 (177 cases) } \\
\hline & & & \multicolumn{2}{|c|}{ No. } & $\%$ \\
\hline \multicolumn{3}{|l|}{$0-8$} & \multicolumn{2}{|c|}{6} & 3 \\
\hline \multicolumn{3}{|l|}{$9-25$} & \multicolumn{2}{|c|}{32} & 18 \\
\hline \multicolumn{3}{|c|}{26 and above } & \multicolumn{2}{|c|}{139} & 79 \\
\hline \multicolumn{3}{|c|}{ Total } & \multicolumn{2}{|c|}{177} & 100 \\
\hline \multicolumn{6}{|c|}{$\begin{array}{l}\text { Table 5: Comparison of severity score after } 2 \text { years of } \\
\text { follow up }\end{array}$} \\
\hline \multicolumn{3}{|c|}{2002 (76 cases) } & & \multicolumn{2}{|c|}{2004 (76 cases) } \\
\hline & Frequency & $(\%)$ & & Frequency & $(\%)$ \\
\hline $0-8$ & 1 & 1 & $0-8$ & 36 & 47 \\
\hline $9-25$ & 17 & 22 & $9-25$ & 29 & 38 \\
\hline $\begin{array}{l}26 \text { and } \\
\text { above }\end{array}$ & 58 & 76 & $\begin{array}{l}26 \text { and } \\
\text { above }\end{array}$ & 11 & 14 \\
\hline Total & 76 & 100 & Total & 76 & 100 \\
\hline
\end{tabular}

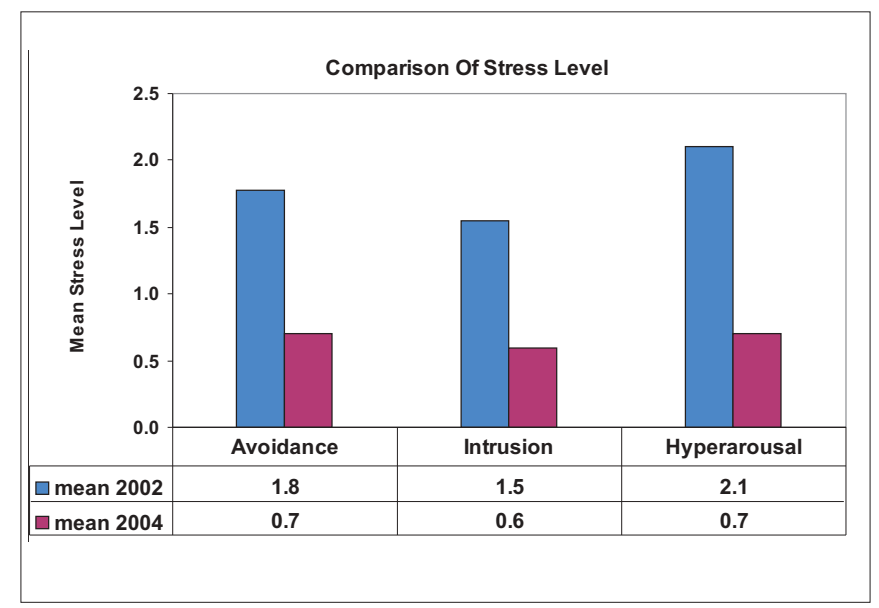

Figure 1: Graph of comparison of mean stress level over time

perceived threat, the relatives success or attempts to minimize injury to oneself or others and the actual loss. ${ }^{[10]}$ Our study focused on trauma ICU admissions because all these stressors were present in relatives of trauma victims. Relatives had little choice of hospital or doctors as patients were usually directly brought to the hospital by bystanders and were often too sick to be transferred. There were mounting bills, uncertainty of an outcome with initial mortality due to trauma and subsequent mortality and morbidity due to infections. Multidisciplinary involvement confused relatives about the 
identity of the treating doctors. There was either too much information or too little and often in language and anatomical terms the relatives found it difficult to comprehend. And above all there was restricted access to the patient.

We believe ours is the first prospective Indian study of its kind and one of the earliest in critical care to focus attention on relatives of ICU patients. It is also one with the longest follow-up of 2 years. The extreme stress and consequent post-traumatic stress disorder in ICU patient's relatives have recently been well-documented. ${ }^{[1-}$ 5] Pochard's group in a prospective multi-centred study of 78 French ICUs reported more than two thirds of family members visiting intensive care unit patients as having symptoms of anxiety or depression during the first days of the hospitalization irrespective of whether the patient was well enough to be discharged or near death. ${ }^{[4]}$ We had similar result in our study with two third of the relatives showing high IESR score in the early days of ICU admission, which persisted in a considerable number of patients even at the end of 2 years.

We used the IES-R to evaluate for PTSD symptoms. The IES-R was designed and validated using a specific time frame of the past 7 days. We have used the same time frame of 7 days for our initial assessment, thus our data are comparable with those collected with this standard time frame. IES-R scores the impact of an event on an individual and gives an assessment of the symptomatic status with respect to the three domains of PTSD symptoms- avoidance, intrusion and hyper arousal occurring as a result of exposure to a traumatic stressor. Similar studies of relatives of ICU patients have used the same scale for diagnosing risk for PTSD. ${ }^{[3,4]}$ A metaanalysis of various studies using IES-R has concluded that cultural differences were relatively insignificant in the development of PTSD as measured by IES-R hence its use was applicable in our patient population ${ }^{[11]}$ Men and women appeared equally stressed in our study with no statistically significant differences in their scores. Incidence of PTSD appears to be similar in males and females ${ }^{[10]}$ although Elie Azoulay group have reported a higher incidence in females.

When Horowitz, Wilner, Alvarez's ${ }^{[9]}$ cutoff point (IES total >26) was used as measure of symptom severity more than two thirds [Table 4] of the relatives showed symptoms of traumatic stress reaction within first week of ICU admission in our study. In Elie Azoulay study ${ }^{[1]}$ a score of 30 was a cause for concern, while Christina Jones group ${ }^{[2]}$ considered a score of 19 to suggest significant risk for PTSD. Different cut off points are likely to create confusion when studies are compared and success of remedial measures assessed.

Weiss recommended using mean score and anchor points score rather than the sum. Here again the mean values in each subscale indicated that more than two third of trauma relatives had symptoms suggestive of PTSD [Table 1]. The correlation between Avoidance and Intrusion subscale was 0.54 in the 177 cases indicating that the subscale were relatively independent of one another, each of them representing a different type of reaction due to stressful event. As in all other reports of PTSD, hyper arousal symptoms were the most common severe psychological disturbance. This is in accordance with the inclusion criteria in the diagnosis of PTSD. ${ }^{[10]}$

These data, when analyzed either way using IES-R cut-off or mean value, show that more than two third relatives were at risk of PTSD in the initial days with a high incidence of persistence of symptoms in moderate to severe grade in about $50 \%$ of the relatives at the end of 2 years. Of these, $14 \%$ had scores above 26 suggesting very high possibility of PTSD. Can this persistence of symptoms at the end of 2 years be another psychological burden of injury? As in Horowitz postulate, intrusion and avoidant symptoms became less frequent with time in our study also. Mean scores on the three subscales (intrusion, avoidance, hyperarrousal) measured after 2 years show a clear shift from severe scale to moderate and mild levels suggesting its linear relation with time, the passage of time reducing the severity of stress in the same group of individuals. About $79 \%$ of the relatives in the present study showed a traumatic stress reaction, which declined significantly $(P<0.05)$ with time mainly because one comes to terms with the event. Persistence of a high score at 2 years suggest that although most individuals recover from psychological effects of a traumatic event, PTSD will develop in substantial proportion. Further psychological tools will be needed to use to confirm the diagnosis of chronic PTSD. In a study by C. Jones and colleagues persistence of high IES-R scores in relatives correlated well with the anxiety levels. ${ }^{[3]}$ 
In an earlier survey, patient's relatives had commented on how they dread summons to the ICU, as it could mean a declaration of death or to sign consent for procedures. Most of the consent forms are always couched with statements of prospects of a patient's deterioration, death or complications during the procedures. This perpetual stress can play havoc with emotional wellbeing. Occasionally suppression of emotion is not possible and anger or guilt can surface. This can translate into dissatisfaction with the ICU care or even be the basis for the development of physical and destructive reflexes resulting in violence against the ICU or hospital staff.

Sessler, ${ }^{[12]}$ in an editorial has eloquently described the universal feelings of the relative of an ICU patient. 'The hospital is not a familiar place and the sights, sounds and smells of the ICU remind one that within this intimidating place, lives hang in balance. Although the doctors and nurses are kindhearted and competent, news of progress is infrequent, often fragmented and at times conflicting. The waiting room is wanting, with little privacy for conversation or to collect one's thoughts. There is a murmur of hushed conversation, punctured by occasional sounds of grieving or forced levity. Soon the battle is apparently turning: the threat of the immediately lifethreatening illness has lessened. However, the protracted campaign of chronic critical illness, with new enemies, such as, nosocomial infections emerge, taxing one's endurance and willpower. Sleep is scarce and fragmented and diet consists of coffee and fast food. Mail piles up and calls go unreturned. Simple joys are not nearly as neither simple nor as joyful. Gut wrenching decisions about critical issues must be made and often provoke emotional conflict and second-guessing, both internally and among the collective family. Usually, there eventually is sufficient recovery for graduation from the ICU to new challenges, but often the devastating loss of this beloved one occurs despite the efforts and anguish of many" The atmosphere is the same in most of our ICUS and patient's relatives are subjected to severe emotional, physical and financial stresses.

Anxiety and depression can also affect the ability of an individual to take decisions and this is of major relevance when family members are involved in decision-making In still another study two thirds of the family members did not want to participate in the decision-making in ICU. ${ }^{[13]} A$ new area of concern is, when only 'technology sustains life', issues such as withdrawing life supports will begin to emerge. The availability of the ISCCM's Position statement ${ }^{[14]}$ on end of life issues will provide guidance to critical care practitioners, but one will have to keep in mind the results of Elie Azoulay study, which concluded that a relative's participation in end of life issues is an independent risk factor for subsequent development of PTSD symptoms.

With relatives having to take major decisions in all critically ill patients, focus is moving from patient centeredness to family centeredness. Critical care family assistance programs have been developed with a goal to respond to the unmet needs of the families, focusing on five categories of family need: information, comfort, support, assurance and anxiety alleviation and need for proximity and accessibility. ${ }^{[15-17]}$ Recent research links inadequate information, information too difficult to understand or when given in insufficient time with high risk for development of PTSD among family members of ICU patients.

Our study was limited to a single center and to relatives of trauma patients only and other scales such as hospital anxiety and depression were not studied relatives needs in our ICU's are also the same. Improvements in communication skills, a waiting area, counseling rooms and compassionate care by the ICU staff are simple measures to reduce stress in the relatives.

\section{Conclusion}

The treatment of trauma patient should not end with the treatment of the patient alone. The relatives are also subjected to the emotional stress, which could cause lasting psychological scars. Our study shows that two third of the trauma ICU relatives are at high risk to develop PTSD, with fourteen percent of them showing residual psychological disorder even after 2 years. Research is needed to devise preventive and early-detection strategies for PTSD especially in those who share in endof-life decisions. Measures such as hospital anxiety and depression scales and hospital satisfaction scales may predict which of these relatives have more possibility of developing PTSD.

Future studies also should examine the relationship between relatives with high PTSD scores and their satisfaction with the quality of treatment in ICU. Another 
area of study would be its impact on the outcome of patients in terms of recovery both physical and emotional, of the patients in their care.

Although all of us have little choice over the given rules, we need not turn them into fences. Simple measures such as a grieving and counseling room, a waiting area with basic amenities can provide comfort to the relatives. Guidelines for consents for procedure, information of seriousness will need to be developed which will reduce the number of consent forms the patient's relatives may have to sign. Above all there is a need for adequate training to doctors on communication with relatives of patients. There is space, time and scope for creativity, compassion and modification in the existing situations so as to reduce stresses to the relatives.

\section{Acknowledgements}

We would like to thank Ms. Sarita Kamble M.Sc, Mr. Manohar Patil M.Sc. for their statistical help.

\section{References}

1. Azoulay E, Pochard F, Kentish-Barnes N, Chevret S, Aboab J, Adrie C, et al. Risk of post-traumatic stress symptoms in family members of intensive care unit patients. Am J Respir Crit Care Med 2005;171:987-94.

2. Jones C, Skirrow P, Griffiths RD, Humphris G, Ingleby S, Eddleston J, et al. Post-traumatic stress disorder-related symptoms in relatives of patients following intensive care. Intensive Care Med 2004;30:456-60.

3. Jones C, Skirrow P, Griffiths RD, Humphris G, Dawson S, Eddleston $\mathrm{J}$, et al. Predicting intensive care relatives at risk of post traumatic stress disorder. Br J Anaesthesia 2000;84:666-7.

4. Pochard F, Darmon M, Fassier T, Bollaert PE, Cheval C, Coloigner $\mathrm{M}$, et al. French FAMIREA study group. Symptoms of anxiety and depression in family members of intensive care unit patients before discharge or death. A prospective multicenter study. J Crit Care 2005;20:90-6.

5. Harvey AG, Bryant RA. The relationship between acute stress disorder and post-traumatic stress disorder: A prospective evaluation of motor vehicle accident survivors. J Consult Clin Psychol 1998;66:507-12.

6. American Psychiatric Association. Diagnostic and statistical manual of mental disorders $\left(4^{\text {th }}\right)$, Washington, DC: 1994.

7. Weiss DS, Marmar CR. The impact of events scale-revised, in assessing psychological trauma and PTSD: A practitioners' handbook. edited by Wilson JP, Keane TM. Guilford: New York; 1997.

8. Mason S, Wardrope J, Turpin G, Rowlands A. The psychological burden of injury: An 18 month prospective cohort study. Emerg Med J 2002;19:400-4.

9. Horowitz MJ, Wilner N, Alvarez W. Impact of event scale: A measure of subjective stress. Psychosomat Med 1979;41: 209-18.

10. Sundin EC, Horowitz MJ. Horowitz's impact of event scale evaluation of 20 years of use. Psychosom Med 2003;65:870-6.

11. Yehuda R. Post-traumatic stress disorder. N Engl J Med 2002;346:108-14.

12. Sessler CN. Caring for those who car the critical care family assistance program. Chest 2005;128:1101-3.

13. Azoulay E, Pochard F, Chevret S, Adrie C, Annane D, Bleichner $G$, et al. Half the family members of intensive care unit patients do not want to share in the decision-making process: A study in 78 French intensive care units. Crit Care Med Sept 2004;32:1832-8.

14. Mani RK, Amin P, Chawla R. Limiting life-prolonging interventions and providing palliative care towards the end-of-life in Indian intensive care units ISCCM's position statement. Indian J Crit Care Med 2003;9:96-105.

15. Guntupalli K, McCaffree DR, Vender J, Clary G, Locicero J $3^{\text {rd }}$. Project director's perspective -The critical care family assistance program. Chest 2005;128:106S-10S.

16. Herridge MS, Angus DC. Acute lung injury: Affecting many lives. N Engl J Med 2005;353:1736-8.

17. Dowling J, Vender J, Guilianelli S, Wang B. A model of familyentered care and satisfaction predictors. The critical care family assistance program. Chest 2005;128:81S-92S.

Source of Support: Nil, Conflict of Interest: None declared 